\title{
Prediction of Performance of Rotary Bottom Hole Assembly For Directional Well
}

\begin{abstract}
Dr.Mohammed S.AL-Jawad; Dr.A.A.AL-Dabaj; Hassan Abdul Hadi Abdul Hussien Petroleum Eng. Depart./ University of Baghdad; Reservoirs Directorate/ Ministry of Oil; Petrolum Eng.Depart./University of baghdad
\end{abstract}

\section{$\underline{\text { Abstract }}$}

A finite element model was constructed to predict inclination tendency for multistabilizer rotary BHA in three dimensions, static condition. The bottom hole assembly was idealized with beam element capable of resisting axial forces, bending moments about the two principal axes, and twisting moments about its centroidal axis. Bit and stabilizer were treated as contact point and restricted from movement in all directions. Each element is loaded with gravity and normal contact forces.

Model validation showed closer agreement between the model and Jiazhi's method (analytic) for slick, single, and two stabilizers BHA, compared to Akgun results. Predictions with finite element model showed that for building assembly, the weight on bit had small effect on bit side force especially in high angle wells. Also inclination tendency (building, dropping) would depend on position of the stabilizer, diameter of drillcollar behind the bit, and number of stabilizers.

Keywords : Directional well;BHA;inclination tendency 
تم بناء نموذج شريحة محدودة ثلاثي الإبعاد لغرض تخمين قابلية بناء الزواية لمجموعة قاع البئر الدورانية المتعددة المثبتات في ظروف السكون.حيث تم معاملة مجموعة قاع البئر كشريحة

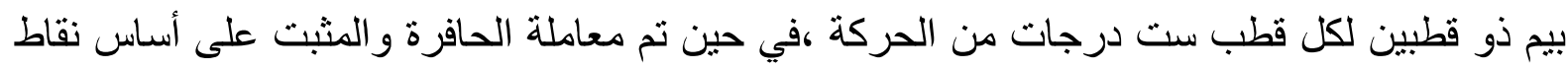

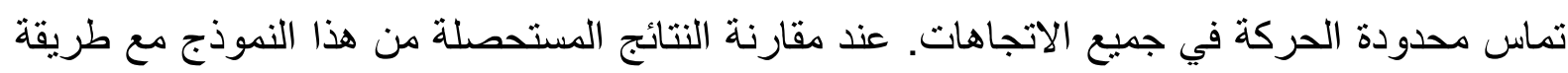

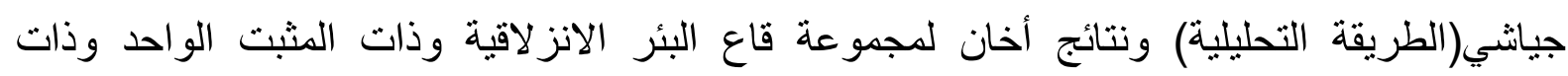

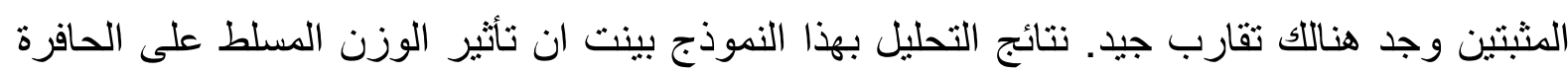

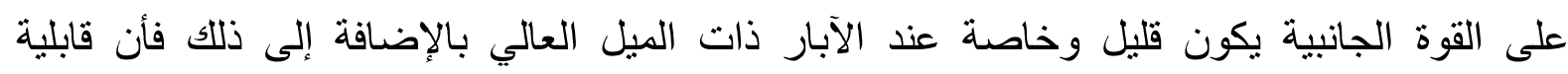
الميل(بناءوهبوط) لمجموعة قاع البئر تعتمد على موقع المثبت وقطر الأنابيب الثقيلة خلف الحافرة و على عدد المثبتات في المجمو عة.

\section{Introduction:}

Directional drilling is the purposeful deflection of a wellbore from the vertical along some preplanned trajectory to a predetermined target. The necessity of directional drilling is usually dictated by economic and environmental concerns [1].

Predicting the actual trajectory of a drilling bit is very complex. Many variables interact causing the bit to follow a certain trajectory. Assembly configuration and dimensions, lithology, dip ,bit type, hole curvature ,bit weight,and rotary speed of the more important parameters that control inclination and azimuth of the bit[2]. 


\section{Journal of Petroleum Research \& Studies}

No.9

This paper presents a 3-D,static finite element model that is capable to predict the inclination tendency (building,dropping holding) for slick, multi stabilizers rotary BHA. The bottom hole assembly was idealized with beam element capable of resisting axial forces, bending moments about the two principal axes, and twisting moments about its centroidal axis. Bit and stabilizer were treated as contact point and restricted from movement in all directions. Each element is loaded with gravity and normal contact forces.

\section{Mathematical Formulation of Rotary Bottom Hole Assembly:}

For the displacement method of analysis, the potential energy $(\pi)$ of finite element system (BHA) is the system strain energy minus the work done by the concentrated forces and moments applied at the nodes. In matrix form this can be expressed as[2]:

$\pi=\frac{1}{2} S^{\rightarrow T}\|K\| S^{\rightarrow}-s^{\rightarrow T} F^{\rightarrow}$

To guarantee equilibrium of the finite element BHA, it is necessary that:

$$
\frac{\partial \pi}{\partial s^{\rightarrow}}=0
$$

Applying the equilibrium condition on Eq.( 1) will result in:

$$
\|K\| S^{\rightarrow}-F=0 \rightarrow
$$

Or as 


$$
F^{\rightarrow}=\|K\| S^{\rightarrow}
$$

Eq. 4 is the force displacement relation of the system which is constructed from assembly of force displacement relationships for an element "e" of the form:

$$
F^{\rightarrow e}=\left\|K^{e}\right\| S^{\rightarrow e}
$$

The force displacement relation (Eq.5) is generated for each element and the master stiffness matrix is assembled to formulate the mathematical relations for external forces acting at any node Consider certain length of BHA composed of number of beam elements. Figure (1) depicts three dimension straight a BHA element of circular cross section with two end nodes. The $\mathrm{x}$-axis (longitudinal axis) passes through the centeroid of the BHA cross section. The $\mathrm{y}$ and $\mathrm{z}$ axes are the principal axes for area moments of inertia of the cross section. Each node was loaded by six external forces which are axial, bending, shear, and three moment forces. The components of the applied nodal forces vector can be written as [3]:

$$
F^{\rightarrow T}=\left\lfloor F_{x} F_{y} F_{z} M_{x} M_{y} M_{z}\right\rfloor
$$

Owing to the applied external load vector, six components of nodal displacements (six degree of freedom) was possessed as shown in figure (2). The component of nodal displacements vector can be written as 


$$
S^{\rightarrow T}=\left[\Delta_{x} \Delta_{y} \Delta_{z} \theta_{x} \theta_{y} \theta_{z}\right]
$$

The stiffness matrix of BHA element in three dimension will be composed of stiffness matrix in $\mathrm{x}-\mathrm{y}$ plane $\left[\mathrm{K}_{\text {bending }}\right]_{\mathrm{xy}}$, stiffness matrix in $\mathrm{x}-\mathrm{z}$ plane $\left[\mathrm{K}_{\mathrm{bending}}\right]_{\mathrm{xz}}$, axial matrix $\left[\mathrm{K}_{\text {axial }}\right]$,and torsional matrix $\left[\mathrm{K}_{\text {torsional }}\right]$. In matrix form this can be expressed as[4]:

$$
\left\|\mathrm{K}^{\mathrm{e}}\right\| \quad\left[\begin{array}{cccc}
{\left[k_{\text {axjas }}\right]} & {[0]} & {[0]} & {[0]} \\
{[0]} & {\left[k_{\text {tending }}\right]_{x y}} & {[0]} & {[0]} \\
{[0]} & {[0]} & {\left[k_{\text {bending }}\right]_{x z}} & {[0]} \\
{[0]} & {[0]} & {[0]} & {\left[k_{\text {tosion }}\right]}
\end{array}\right]
$$

A general three dimensional BHA element is capable of both axial and torsional deflections as well as two-plane bending. Adding the torsional stiffness matrix to the general BHA element (Eq. 8), the element equations become:

$$
\left[\begin{array}{cccc}
{\left[k_{\text {axial }}\right]} & {[0]} & {[0]} & {[0]} \\
{[0]} & {\left[k_{\text {bending }}\right]_{x y}} & {[0]} & {[0]} \\
{[0]} & {[0]} & {\left[k_{\text {bending }}\right]_{x z}} & {[0]} \\
{[0]} & {[0]} & {[0]} & {\left[k_{\text {torsion }}\right]}
\end{array}\right]\left[\begin{array}{c}
u_{1} \\
u_{2} \\
y_{1} \\
\theta_{z 1} \\
y_{2} \\
\theta_{z 2} \\
w_{1} \\
\theta_{y 1} \\
w_{22} \\
\theta_{y 2} \\
\theta_{x 1} \\
\theta_{x 2}
\end{array}\right\}=\left\{\begin{array}{c}
J_{x 1} \\
f_{x 2} \\
f_{y 1} \\
M_{z 2} \\
f_{y 2} \\
M_{z 2} \\
f_{z 1} \\
M_{y 1} \\
f_{z 2} \\
M_{y 2} \\
M_{x 1} \\
M_{x 2}
\end{array} \mid\right.
$$

In expanded form, the 3-D BHA stiffness matrix can be written as follows [5]: 


$$
\left[\mathrm{K}_{\mathrm{e}}\right]=\left[\begin{array}{cccccccccccc}
\frac{A E}{L} & 0 & 0 & 0 & 0 & 0 & \frac{-A E}{L} & 0 & 0 & 0 & 0 & 0 \\
0 & \frac{12 E I_{z}}{L^{3}} & 0 & 0 & 0 & \frac{6 E I_{z}}{L^{2}} & 0 & \frac{-12 E I_{z}}{L^{3}} & 0 & 0 & 0 & \frac{6 E I_{z}}{L^{2}} \\
0 & 0 & \frac{12 E I_{y}}{L^{3}} & 0 & \frac{-6 E I_{y}}{L^{2}} & 0 & 0 & 0 & \frac{-12 E I_{y}}{L^{3}} & 0 & \frac{-6 E I_{y}}{L^{2}} & 0 \\
0 & 0 & 0 & \frac{G J}{L} & 0 & 0 & 0 & 0 & 0 & \frac{-G J}{L} & 0 & 0 \\
0 & 0 & \frac{-6 E I_{y}}{L^{2}} & 0 & \frac{4 E I_{y}}{L} & 0 & 0 & 0 & \frac{6 E I_{y}}{L^{2}} & 0 & \frac{2 E I_{y}}{L} & 0 \\
0 & \frac{6 E I_{z}}{L^{2}} & 0 & 0 & 0 & \frac{4 E I_{z}}{L} & 0 & \frac{-6 E I_{z}}{L^{2}} & 0 & 0 & 0 & \frac{2 E I_{z}}{L} \\
\frac{-A E}{L} & 0 & 0 & 0 & 0 & 0 & \frac{A E}{L} & 0 & 0 & 0 & 0 & 0 \\
0 & \frac{-12 E I_{z}}{L^{3}} & 0 & 0 & 0 & \frac{-6 E I_{z}}{L^{2}} & 0 & \frac{12 E I_{z}}{L^{3}} & 0 & 0 & 0 & \frac{-6 E I_{z}}{L^{2}} \\
0 & 0 & \frac{-12 E I_{y}}{L^{3}} & 0 & \frac{6 E I_{y}}{L^{2}} & 0 & 0 & 0 & \frac{12 E I_{y}}{L^{3}} & 0 & \frac{6 E I_{y}}{L^{2}} & 0 \\
0 & 0 & 0 & \frac{-G J}{L} & 0 & 0 & 0 & 0 & 0 & \frac{G J}{L} & 0 & 0 \\
0 & 0 & \frac{-6 E I_{y}}{L^{2}} & 0 & \frac{2 E I_{y}}{L} & 0 & 0 & 0 & \frac{6 E I_{y}}{L^{2}} & 0 & \frac{4 E I_{z}}{L} & 0 \\
0 & \frac{6 E I_{z}}{L^{2}} & 0 & 0 & 0 & \frac{2 E I_{z}}{L} & 0 & \frac{-6 E I_{z}}{L^{2}} & 0 & 0 & 0 & \frac{4 E I_{z}}{L}
\end{array}\right]
$$

Which is $12 \times 12$ symmetric matrix composed of the individual stiffness matrices representing axial loading, two-plane bending, and torsion.

\section{Validation of the Model :}

The finite element model is first verified by comparing its results with analytical method[6], and Akgun[7] results (axisymmtric element) for two dimensions, in term of bit side force and tangency point. Three types of rotary BHA are considered in the comparisons, which are slick, single stabilizer, and two stabilizers. For slick BHA, figures (3-4) shows a good agreement between these methods, but for single and two stabilizers BHA, there is a noticeable difference between them as shown in figures (5-8) ,Table (1-3) provides the percentage difference between analytical and the current finite method. 


\section{Journal of Petroleum Research \& Studies}

\section{Effect of Weight on Bit:}

Figure (9) shows the effect of applied WOB on the bit side force in term of hole inclination for single stabilizer BHA. At low hole angle, this BHA exhibited low response (increasing) building tendency with WOB due to increase of positive side force (building force). When the hole angle increase, the relationship is almost horizon. This behavior may be attributed to increasing of negative side force with inclination which opposite the effect of WOB and reduce its effect. Thus the effect of applied WOB in high angle wells on side force will be very small.

\section{Effect of Stabilizer Position:}

Many BHA configurations contain stabilizer placed some where in drillstring. This practice represents easiest way to control the point of tangency. The mechanism of stabilizer could be explained by reviewing figure (10). As the plot indicated, placing stabilizer near the bit caused highest building or positive side force. As the stabilizer is moved away from the bit, the bit side force decreased and reach zero at particular distance. At this distance, the BHA has holding tendency. Beyond holding tendency, bit side force become negative and has dropping tendency (called pendulum BHA) and reached to maximum negative value. At this maximum negative value, the drill collar achieved tangency between the bit and the stabilizer. A continued increasing of the distance reduces the negative side force until it approaches the behavior of collar-only assembly.

\section{Effect of Collar Diameter:}

Figure (11) Shows the effect of changing collar diameter above the stabilizer on building force for building assembly. The first curve is for all diameters 6.75 in. The second and third curves for collar of diameter 6 in of different lengths ( $30 \mathrm{ft}$ and $60 \mathrm{ft}$ ) 
beyond the stabilizer. The fourth and fifth curves are for big collar ( 8 in) for the same lengths (30 ft and $60 \mathrm{ft}$ ). A sizable effect on bit side force is noticed when adjusting diameter behind the stabilizer. A reduction in building force is noticed when using large size ( 8 in). Also lengthened the portion of changed collar diameter will caused some improvement in building force(bit side force).

\section{Effect of No. of Stabilizers:}

Figure (12) shows the performance of three pendulum bottom hole assemblies with different number of stabilizers. The first curve for single stabilizer, second curve for two stabilizers, and third curve for three stabilizers. As it shown, increasing number of stabilizers would strengthen the dropping tendency of this BHA. This behavior may be attributed to reduction in positive bending force and increasing the negative side force. 


\section{Journal of Petroleum Research \& Studies}

\section{Conculsions:}

Based on the obtained results, the following items have been drawn as the main conclusions for this study:

1- The finite element model of rotary BHA give closer results to analytical method for slick, single, and two stabilizers BHA more than axisymmtric model.

2- For single stabilizer building BHA, adjusting the weight on bit would cause small improving of building force at low angle. Increasing the inclination angle will limit this effect.

3- In single stabilizer BHA, placing stabilizer near the bit would cause building force. When the stabilizer moved away from the bit, the inclination tendency changed from building to dropping.

4- Reducing the diameter of drill collar behind the bit will affect the bit side force (increasing building force).

5- Using multistabilizer bottom hole assembly and lengthened distance between first and second stabilizer would increase the bit side force.

\section{Nomenclature:}

$s \rightarrow$ : nodal displacement vector.

$\mathrm{s}^{\rightarrow \mathrm{T}}$ : transpose of nodal-displacement vector

$\|K\|:$ stiffness matrix of finite element assembly

$\mathrm{F}^{\rightarrow}$ : applied nodal force vector

$\mathrm{F}_{\mathrm{x}}, \mathrm{F}_{\mathrm{y}}, \mathrm{F}_{\mathrm{z}}$ : forces acting along $\mathrm{x}, \mathrm{y}$, and $\mathrm{z}$ axes .

$\mathrm{M}_{\mathrm{x}}, \mathrm{M}_{\mathrm{y}}, \mathrm{M}_{\mathrm{z}}$ : moments about $\mathrm{x}, \mathrm{y}$, and $\mathrm{z}$ axes.

$\Delta_{\mathrm{x}}, \Delta_{\mathrm{y}}, \Delta_{\mathrm{z}}$ : Nodal displacements in $\mathrm{x}, \mathrm{y}$, and $\mathrm{z}$ axes.

$\Theta_{\mathrm{x}}, \theta_{\mathrm{y}}, \theta_{\mathrm{z}}:$ Rotational displacements about $\mathrm{x}, \mathrm{y}$, and $\mathrm{z}$ axes. 


\section{References:}

1. Wiggins,M.L;and Juvkam,H.C.,"Simplified Equations for Planning Directional and Horizontal Wells",SPE.21261,1990.

2. Millheim, K.and Apostal, M.C., "Bottom Hole Assembly Analysis Utilizing the Finite Element Method", JPT. (Feb.1978),265-273.

3. Millheim, K., "The Effect of Hole Curvature on the Trajectory Borehole", SPE.7779, 1977.

4. David, V.H., "Fundamentals of finite Element Analysis", McGraw- Hill, (2004).

5. Prezeminiecki, J.S., "Theory of Matrix Structural Analysis", McGraw- Hill, New York, (1968).

6. Jiazhi, B., "Bottom Hole Assembly Problems Solved by Beam - Column Theory", SPE.10561, 1982.

7. Akgun, F.,"A Finite Element Model for Analyzing Horizontal Well BHA Behavior", JPSE, 2003 


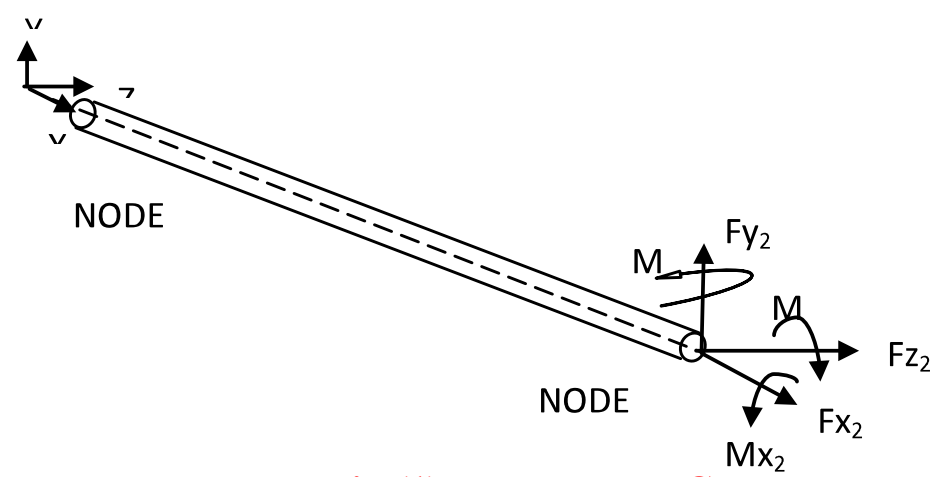

Fig.(1) Nodal Force Components of BHA Element

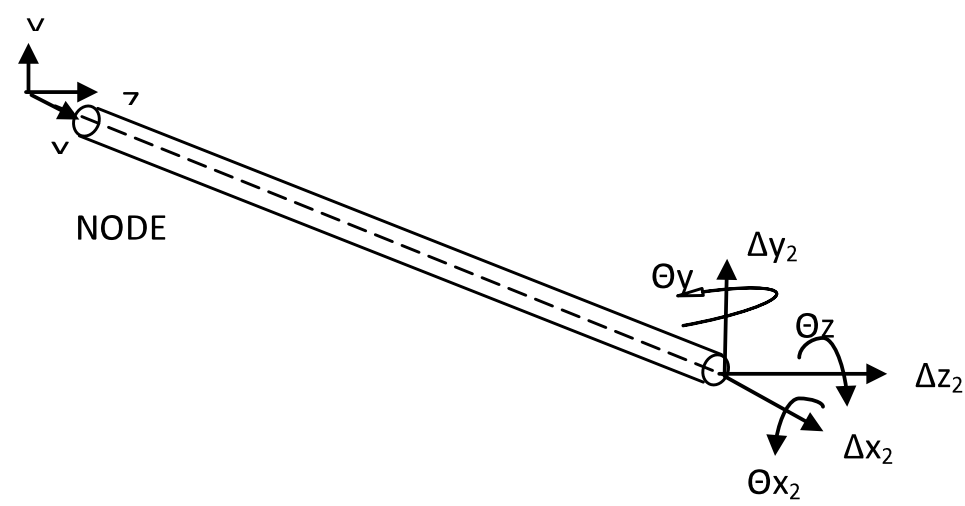

Fig. (2) Nodal Displacements Components of BHA Element.

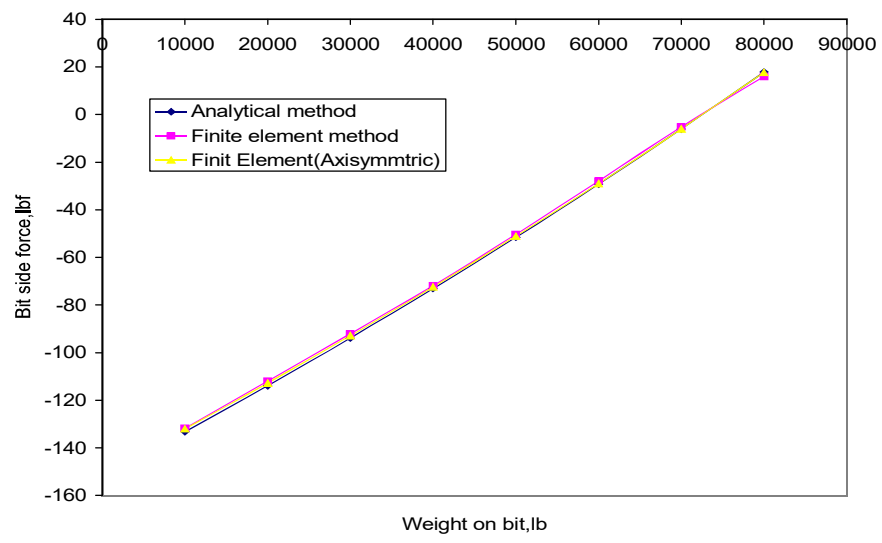

Fig.(3) Bit Side Force From Analytical and Finite Element Methods, Slick 


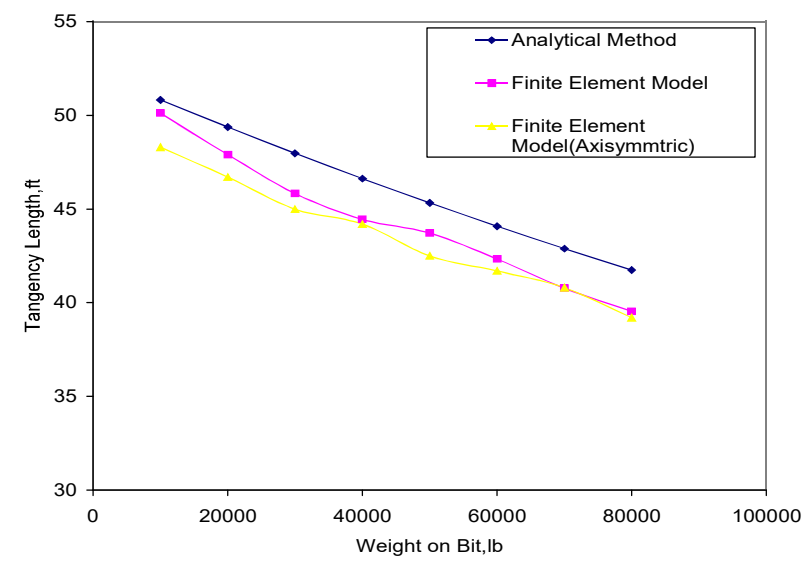

Fig.(4) Tangency Length from Analytical and Finite Element Methods, Slick BHA.

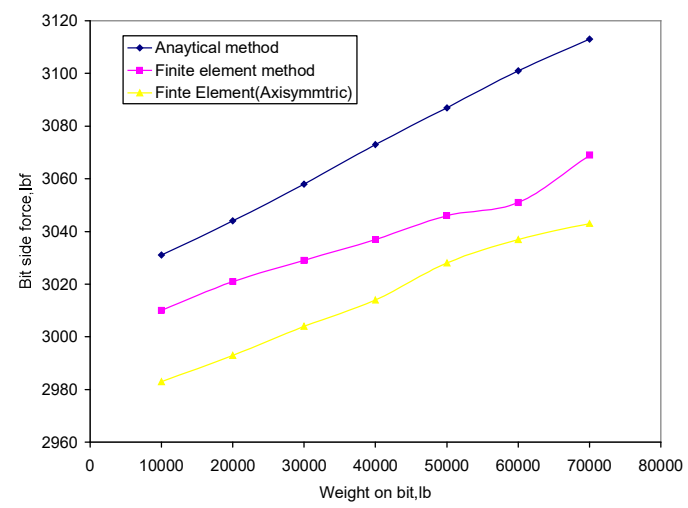

Fig.(5) Bit Side Force From Analytical and Finite Element Methods, Single Stabilizer BHA

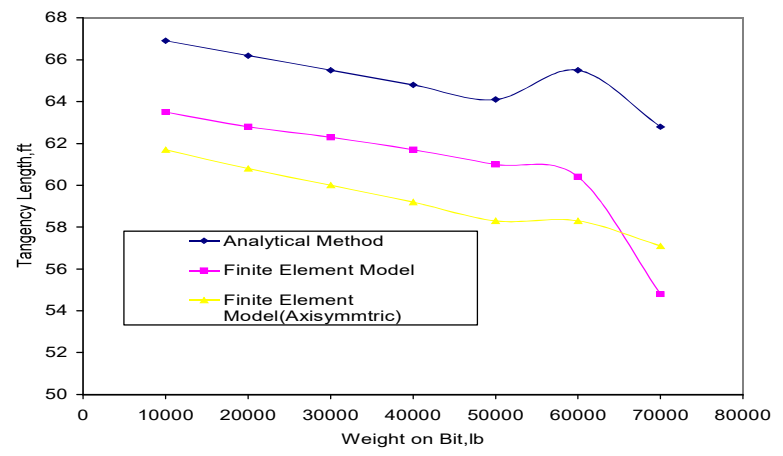

Fig.(6) Tangency Length From Analytical and Finite Element Methods, Single Stabilizer BHA. 


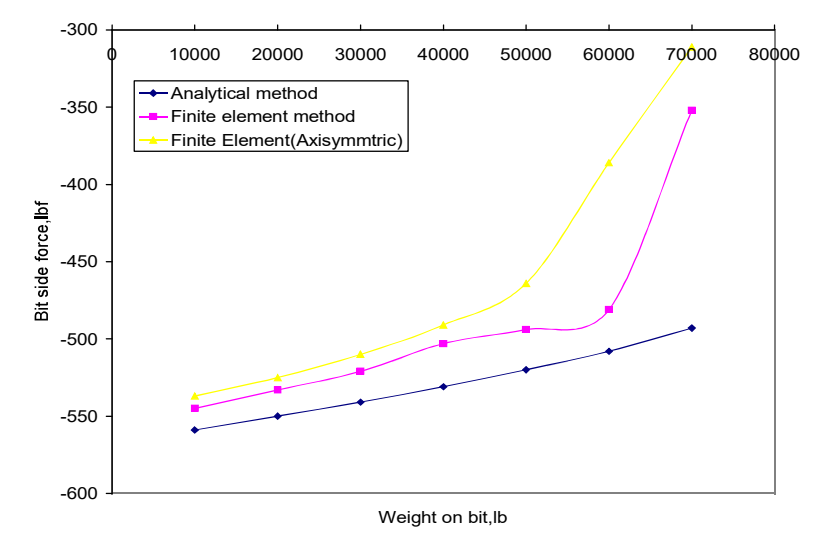

Fig.(7) Bit Side Force Results from Analytical and finite Element Methods, Two Stabilizers BHA.

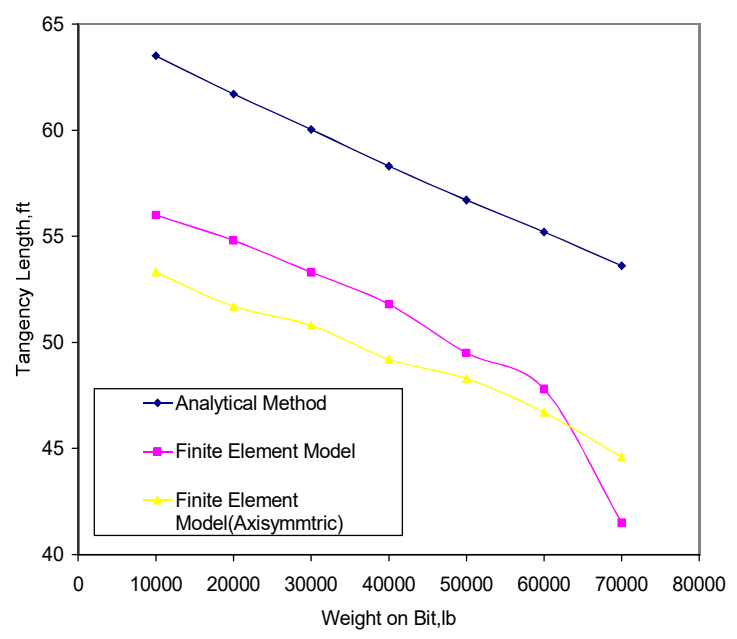

Fig. (8) Tangency Length Results From Analytical and Finite Element Methods, Two Stabilizers B

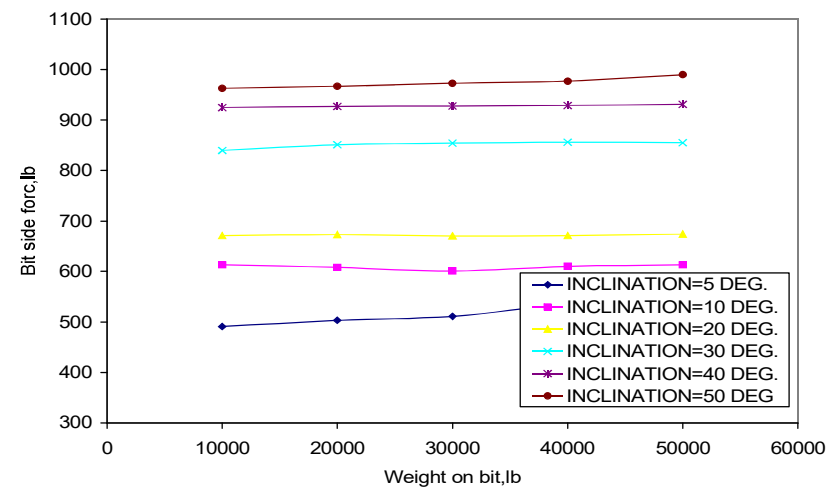

Fig. (9) Effect of Weight on Bit on Side Force (Build Assembly). 


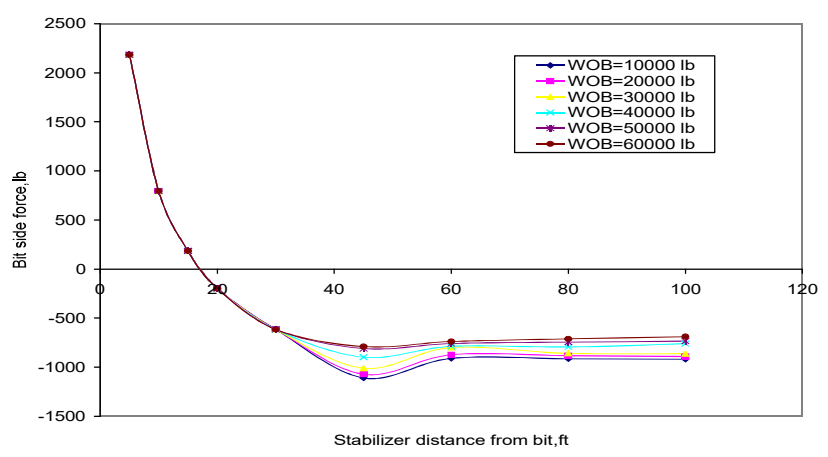

Fig.(10) Effect of Stabilizer Position on Bit Side Force.

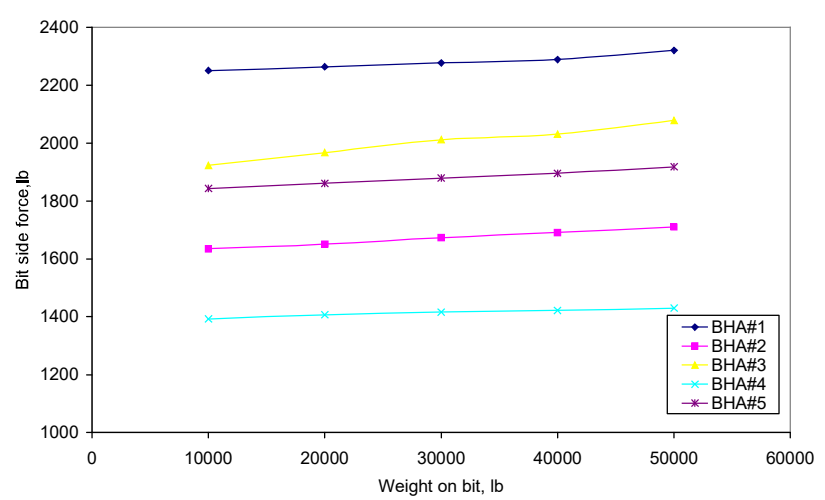

Fig.(11) Effect of Collar Diameter on Bit Side Force

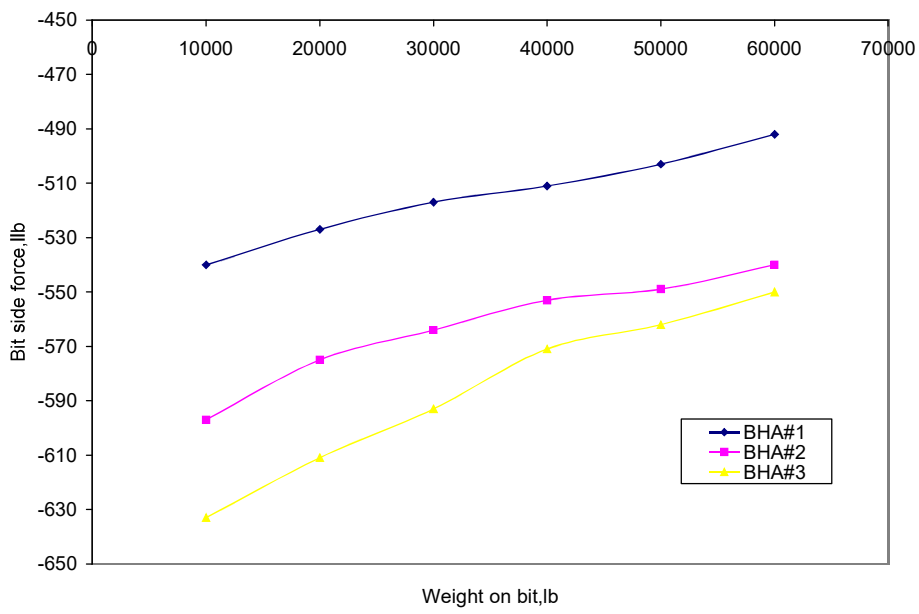

Fig.(12) Effect Number of Stabilizers on Bit Side Force. 


\section{Journal of Petroleum Research \& Studies}

No.9

Table (1) Percentage difference between analytical and finite element methods for slick BHA

\begin{tabular}{|c|r|r|}
\hline WOB(lb) & \multicolumn{1}{|c|}{$\begin{array}{c}\text { Bit side } \\
\text { Force(\%) }\end{array}$} & $\begin{array}{r}\text { Tangency } \\
\text { Length(\%) }\end{array}$ \\
\hline 10000 & 0.010661 & 0.013968 \\
20000 & 0.016857 & 0.029769 \\
30000 & 0.019063 & 0.04481 \\
40000 & 0.016826 & 0.046751 \\
50000 & 0.025 & 0.035517 \\
60000 & 0.043151 & 0.039701 \\
70000 & 0.145902 & 0.049429 \\
\hline
\end{tabular}

Table (2) Percentage difference between analytical and finite element methods for single stabilizer BHA

\begin{tabular}{|c|r|r|}
\hline WOB(lb) & $\begin{array}{c}\text { Bit side } \\
\text { force(\%) }\end{array}$ & $\begin{array}{r}\text { Tangency } \\
\text { Length(\%) }\end{array}$ \\
\hline 10000 & 0.006928 & 0.050964 \\
30000 & 0.007556 & 0.05136 \\
40000 & 0.011715 & 0.04784 \\
50000 & 0.013282 & 0.048362 \\
60000 & 0.016124 & 0.077863 \\
70000 & 0.014134 & 0.127389 \\
\hline
\end{tabular}

Table (3) Percentage difference between analytical and finite element methods for two stabilizer BHA

\begin{tabular}{|r|r|r|}
\hline WOB(lb) & $\begin{array}{r}\text { Bit side } \\
\text { force(\%) }\end{array}$ & $\begin{array}{r}\text { Tangency } \\
\text { length(\%) }\end{array}$ \\
\hline 10000 & 0.025045 & 0.11811 \\
20000 & 0.030909 & 0.111831 \\
30000 & 0.036969 & 0.111963 \\
40000 & 0.052731 & 0.111492 \\
50000 & 0.05 & 0.126984 \\
60000 & 0.05315 & 0.134058 \\
70000 & 0.286004 & 0.225746 \\
\hline
\end{tabular}

